\title{
Sergio Moro negacionista? Operação Lava Jato, transparência atualista e negação da política
}

Is Sergio Moro a Negationist? Operation "Lava Jato", Updatism Transparency and Negation of Politics

\author{
Mateus Henrique de Faria Pereira ${ }^{*}, 1$ \\ Daniel Pinha Silva**,
}

\section{RESUMo}

Este artigo desenvolve a hipótese de que a narrativa de Sergio Moro à frente da Operação Lava Jato se movimentou em torno de modalidades de negacionismo, revisionismo e negação. A negação da política é o pressuposto a partir do qual as investigações deveriam se movimentar. Essa narrativa foi produzida entre 2004 e 2020 por uma força "despolitizada" e moralizadora, vinda de órgãos do judiciário e disseminada pela grande imprensa. Paralelamente à operação italiana Mãos Limpas, Moro e seus acólitos admitiam uma forma de intervenção nos acontecimentos políticos marcada pela ideia de que a operação não era apenas jurídico-investigativa, mas um movimento político capaz de produzir um diagnóstico, uma agenda e mesmo uma "revolução" no país. O evento permitiu a ascensão de Bolsonaro ao centro do sistema político, incorporando

\section{Abstract}

This article develops the hypothesis that Sergio Moro's narrative at the head of Operation "Lava Jato" was built around the modalities of negationism, revisionism and negation. The denial of the politics is the assumption from which investigations should move. This narrative was produced between 2004 and 2020 by a "depoliticized" and moralizing force coming from the judicial bodies and disseminated by the mainstream press. Parallel to the Italian operation "Mani Pulite", Moro and his acolytes admitted a form of intervention in political events marked by the idea that the operation was not only legal-investigative, but a political movement capable of producing a diagnosis, an agenda and even a "revolution" in the country. The event allowed Bolsonaro to rise to the center of the political system, incor-

\footnotetext{
* Universidade Federal de Ouro Preto (UFOP), Mariana, MG, Brasil. matteuspereira@gmail.com $<$ http://orcid.org/0000-0001-7489-7365>

** Universidade do Estado do Rio de Janeiro (UERJ), Rio de Janeiro, RJ, Brasil. danielpinha@yahoo. com.br <https://orcid.org/0000-0002-6460-5610>
} 
o negacionismo e a negação da política oriundos do clima geral.

Palavras-chave: Sergio Moro; Lava Jato; Atualismo; Transparência; Negacionismo; Mãos Limpas. porating negationism and denial of politics from the general scenario. Keywords: Sergio Moro; Lava Jato; Updatism; Transparency; Negationism; Mani pulite.

Para nosso amigo Henrique Estrada Rodrigues

O herói da transparência só se constrói à luz de muita obscuridade (Henrique Estrada Rodrigues, 2021).

Toda história está sob a pressão do tempo. Para aliviar e corrigir essa pressão, a fronteira entre segredo e publicidade sempre precisa ser redefinida e restabelecida. O caso Watergate foi uma violação criminosa dessa fronteira (Reinhart Koselleck, 2014).

A hipótese central desenvolvida neste ensaio é a de que a narrativa empreendida e simbolizada por Sergio Moro à frente da Operação Lava Jato se movimentou em torno de modalidades de negacionismo, revisionismo e negação. A negação da política é entendida como pressuposto a partir do qual as investigações deviam se movimentar. Essa narrativa negacionista da política foi produzida entre 2014 e 2020, por uma força “despolitizada" e moralizadora, vinda de órgãos do judiciário, traduzida e disseminada pela grande imprensa na opinião pública. Imbuído de espírito de heroísmo revolucionário, Moro e seus seguidores admitiam uma forma de intervenção nos acontecimentos políticos, dispostos ao público em tempo real, marcada pela ideia de que a Lava Jato não era apenas uma Operação jurídico-investigativa, mas um movimento político maior, capaz de produzir um diagnóstico, uma agenda e, talvez, até uma "revolução" para o Brasil.

A partir do princípio da transparência foram realizadas diversas ações de combate à corrupção tendo em vista a publicidade e a espetacularização. Tais práticas construíram um clima capaz de ampliar a percepção pública favorável ao enfrentamento dos desvios de conduta realizados por políticos profissionais, 
como se esta percepção pudesse superar a factualidade do referente; operando, assim, um procedimento negacionista, pois se admitiam formas de torção da realidade animadas pelo senso de missão que orientava os princípios lavajatistas, simbolizados na figura de Sergio Moro e estendidos a importantes segmentos do poder judiciário, como, por exemplo, o ex-Procurador Geral da República Rodrigo Janot.

Nesse sentido, partimos da seguinte distinção entre negacionismo, revisionismo e negação:

Negação: contestação da realidade, fato ou acontecimento que pode levar à dissimulação, à falsificação, à fantasia, à distorção e ao embaralhamento. Em geral, percebemos uma dissimulação e uma distorção da factualidade que, ou procura negar o poder de veto das fontes, ou fabrica uma retórica com base em "provas" imaginárias e/ou discutíveis/manipuladas. Revisionismo: interpretação livre que não nega necessariamente os fatos, mas que os instrumentaliza para justificar os combates políticos do presente a fim de construir uma narrativa "alternativa" que, de algum modo, legitima certas dominações e violências. Negacionismo: radicalização da negação e/ou do revisionismo. Falsificação do fato (Pereira, 2015, pp. 865-866. Cf., também, entre outros, Valencia-García, 2020; Bauer; Nicolazzi, 2016; Traverso, 2017; Trucker, 2007; Virno, 2013; Meneses, 2020).

Essas distinções nos ajudarão a argumentar que discursos e textos do herói da transparência - Sergio Moro - simbolizam a emergência de uma modalidade específica de negação no Brasil contemporâneo, pois, dentre outros fatores, ela se articula com uma atualização do discurso da transparência. Nessa direção, essa negação se atualizou em função da atualidade, isto é, conforme as correntes da "opinião pública", ao mesmo tempo em que promoveu o negacionismo político, sendo o seu principal legado a emergência e a consolidação do negacionismo político bolsonarista: a implosão do sistema político, em guerra permanente contra a democracia, enquanto modus operandi capaz de produzir uma corrosão democrática de dentro do próprio sistema, efetivada por meio de uma aliança estratégica entre diversos setores da direita e da extrema-direita, a partir do entrelaçamento de diversas durações e contingências históricas (Cf., também, entre outros, Pereira; Araujo, 2020; Avritzer, 2020; Aarão Reis, 2020; Nobre, 2020).

A negação da política, cristalizada no antipetismo e traduzida no discurso lavajatista, criou as condições para que a cruzada bolsonarista contra a de- 
mocracia se movimentasse da margem ao centro, isto é, realizando a passagem do ressentimento antidemocrático inconformado com o fim da Ditadura, atuando nas fendas do regime (Cf., entre outros, Pinha, 2020 e Bauer, 2020) para sustentar e acelerar o processo de reformas do Estado, inseridas em um programa neoliberal e conservador.

Cabe ainda dizer que essas ações e esse clima foram construídos a partir de uma legitimação histórica, ou melhor, de um tipo impreciso de revisionismo histórico: a leitura empreendida por Moro e membros da Lava Jato sobre a história da Operação Mãos Limpas, na Itália, e seus desdobramentos. Isto é, a relativização da "explosão" do sistema político e, por consequência, a abertura de caminho para a edificação de uma liderança outsider e antidemocrática, caso de Silvio Berlusconi, e a inexistência de herança institucional efetiva no combate à corrupção na Itália.

\section{I}

Mateus Pereira e Valdei Araujo definem fragmentos de nossa atual experiência do tempo a partir da emergência da palavra atualização/update. $\mathrm{O}$ atualismo seria uma forma de presente que se quer atualizar automaticamente em função da própria atualidade: "essa atualidade se vê em toda a história, seja do presente, seja do futuro, mas é uma identificação como uma variedade do mesmo que 'atualiza em função da atualidade'” (Pereira; Araujo, 2018, p. 124). Concordando com a definição supracitada, nos perguntamos se a transparência seria um dos projetos de futuro de nossa condição atualista.

Essa pergunta nos pareceu necessária, em especial, a partir de uma das definições de democracia, utilizada por Sergio Moro, que respaldou, em 2016, a exposição de conversas gravadas entre o ex-presidente Lula e a então presidenta Dilma Rousseff, fora do período autorizado judicialmente: "A democracia em uma sociedade livre exige que os governados saibam o que fazem os governantes, mesmo quando estes buscam agir protegidos pelas sombras" (Rodas, 2016), afirma Moro.

Em um mundo "atualista", a fronteira entre o público e o privado, como mencionada por Koselleck na epígrafe, estaria sendo redefinida com maior intensidade, ocasionando diversas composições e reconfigurações? Ou será que essa fronteira praticamente não existe mais, pois estamos vivendo no 
reino da constante "violação criminosa" (para evitar o controverso termo exceção)?

Com o propósito de iluminar essas questões, podemos dizer que a atual reorganização e/ou dissolução dos domínios do público e do privado, a exibição excessiva e a abundância de informações têm, cada vez mais, produzido demandas por transparência.

Como afirmou Ivar Hartmann, professor da FGV, em 2016, para defender os procuradores da Operação Lava Jato de parcialidade, no momento da apresentação de denúncia contra o ex-presidente Lula utilizando-se do famoso Power Point: "transparência é positiva em qualquer caso." (Alessi, 2016).

Para Byung-Chul Han (2014), o tempo se converte em transparência quando se nivela em sucessão de um presente disponível. Um tempo transparente seria, em tese, carente de destino e de evento. A esse respeito, Simmel formulou uma advertência que talvez seja mais do que atual: "se a transparência recíproca completa fosse possível, as relações dos seres humanos uns com os outros se modificariam de maneira inimaginável” (Simmel, 2009, p. 224). $\mathrm{E}$, nesse sentido, nos perguntamos, junto com Vincent: "será que queremos mesmo, como dizemos, a transparência do outro?" (Vicent, 1995, p. 185). Ao assistirmos à seletividade da Operação Lava Jato e conhecermos as suas obscuridades, evidenciadas no escândalo da Vaza Jato, em $2019^{3}$, uma questão se coloca: a boa transparência é a do outro?

A política, enquanto uma ação estratégica, necessita do segredo, pois "o segredo é um dos fundamentos da estabilidade social” (Vincent, 1995, p. 185). Assim, podemos dizer que, ao longo do auge da Operação Lava Jato, muitas vezes, o discurso da transparência serviu para negar a política em um mundo que, cada vez mais, valoriza a exposição. Ao que parece, na era do Facebook é preciso se expor para existir: "na sociedade exposta, cada sujeito é o seu próprio objeto de publicidade. Tudo se mede em seu valor de exposição" (Han, 2014, p. 29).

A particularidade do que Han chama de panóptico digital está no fato de que os seus moradores colaboram, de maneira ativa, para a sua construção e conservação, enquanto eles mesmos se exibem e se desnudam. Nesse habitat, a vítima se transforma em algoz e vice-versa, com certa frequência e intensidade. Nesse sentido, estamos vivendo uma mutação importante nas sociedades democráticas, pois a esfera pública, como espaço de ação comum, se metamorfosearia em um espaço de exposição. ${ }^{4}$ 
É nesse contexto que devemos pensar a atualização do escândalo político na era da internet. O escândalo moderno, segundo Thompson (2010), é baseado no aparecimento, no domínio público, de práticas e informações de domínio privado, aliado à percepção de que tais práticas são transgressoras ou impróprias, bem como à sua grande visibilidade e condenação pela mídia. $\mathrm{O}$ problema atual é que houve uma ampliação da visibilidade e do auditório do escândalo, pois os limites entre o público e o privado cada vez mais passam a ser - em especial depois do acontecimento internet -, imprecisos e em mutação constante, dado que essa fronteira se tornou porosa, contestada, negociada e disputada.

Tendo em vista as imprecisões e o rápido trânsito atual das fronteiras entre o público e o privado, as relações de poder passaram a ser contestadas e abaladas com maior frequência e intensidade. Assim, "os atos pela liberdade de informação, que ganharam força em muitas sociedades ocidentais nas últimas décadas, são peças-chave no cenário em que emergem as novas guerras de informações" (Thompson, 2010, p. 31). Essas guerras, como o escândalo das despesas dos membros do Parlamento Britânico (2009), podem - como foi também o caso da Operação Lava Jato - levar "partes inteiras da vida política e social ao caos" (Thompson, 2010, p. 35). Há, assim, algo de novo, ou talvez uma radicalização do papel das formas mediadas, surgidas desde a difusão da imprensa, pois, cada vez mais, é a nossa capacidade de dar visibilidade e/ou de ocultar que está difícil de controlar. Portanto, do ponto de vista político, cria-se um campo propício para o uso do discurso atualista da transparência como arma política.

Uma questão que revela a ambivalência contemporânea do assunto é: para que manter segredo se "alguém" ou uma empresa já detém e negocia nossos dados privados? Sem dúvida alguma, há mais problemas relacionados à transparência privada do que em relação à chamada "transparência pública". Ainda assim, países com poucas políticas de combate à corrupção e liberdades democráticas podem se situar bem em índices de "transparência pública", como é o caso da Transparência Internacional (Avritzer, 2016). ${ }^{5}$ Um dos problemas é que o combate à corrupção, em geral, é cheio de paradoxos. O avanço e o aprimoramento são sempre importantes, ao mesmo tempo em que revelam, cada vez mais, a privatização do setor público.

Nesse sentido, é muito difícil dizer se a corrupção é maior ou menor em 
determinados períodos, como, por exemplo, em relação à Ditadura Militar - ao contrário, portanto, do que pensava a maioria dos brasileiros em 2017 (Fujita; Marchao, 2017). Afinal, “a corrupção é um fenômeno secreto, e as evidências sobre ela são indiretas. A maior parte dos índices que medem a corrupção é baseada na percepção sobre sua existência, que é tanto maior quanto mais a corrupção é combatida" (Avritzer, 2016, p. 9).

Consultando a base de dados do Google Livros, observamos que, na década de 1980, o uso da palavra transparência duplica em aparições. Assim, é provável que, no mundo e no Brasil, a palavra transparência tenha se disseminado, a partir dessa década, pela tradução da palavra russa glasnost. Para Yurchak (2005), a perestroika e a glastnost, de Gorbatchev, são uma resposta à crise, a partir da década de 1970, de uma tentativa política de "estatização do tempo". Um projeto paradoxal de emancipação do homem, inclusive do tempo, mas atravessado pelo controle da sociedade pelo partido e pelo Estado.

Ao mesmo tempo, o contexto pós-stalinista possibilitou a emergência de um imaginário positivo e liberal do "Ocidente". A emergência desse Oeste imaginário ocorre pari passu em que a visão de um futuro triunfante, hegemônico, observada até os anos 1960, dá lugar à sensação de um presente em crise. $\mathrm{O}$ acesso às informações, testemunhos e publicações dos dissidentes, tendo em vista a abertura operada pela política da glasnost, parece ter tido efeito catalizador, transformador e até destrutivo de certos pontos de vista.

\section{II}

A independência judiciária, interna e externa, a progressiva deslegitimação de um sistema político corrupto e a maior legitimação da magistratura em relação aos políticos profissionais foram, portanto, as condições que tornaram possível o círculo virtuoso gerado pela operação manipulite (Moro, 2004, p. 58).

Considerando o grau de deterioração da coisa pública, revelado no mensalão e na Operação Lava-Jato, não deixa de ser justificado algum ativismo judicial contra a corrupção. Não se trata de defender interpretações criativas da Constituição. Trata-se de defender a igual e imparcial aplicação da lei contra o abuso sistemático do poder para fins privados. A lei deve valer para todos. O ativismo reside na estrita aplicação da lei mesmo contra interesses especiais. No Brasil, tal postura é revolucionária (Moro, 2018). 
Escritas em momentos diferentes e comentando o caso italiano e o caso brasileiro, respectivamente, as duas passagens acima revelam traços decisivos do discurso de Sergio Moro acerca da intrínseca relação entre o combate à corrupção e a negação da política. O que está em jogo, nas leituras sobre a Operação Mãos Limpas e sobre a Operação Lava Jato, é a reiteração de um mesmo argumento: o ativismo judicial.

Certamente, a leitura sobre a operação italiana Mãos Limpas foi a que mais nos ajudou a compreender certas ideias de transparência e ativismo que fundamentam a ação de negação da política, simbolizada nas práticas da Operação Lava Jato e nos textos e ações de Sergio Moro. Podemos dizer que, no artigo "Considerações sobre a operação Mani Pulite", de 2004, Sergio Moro dispõe as linhas mestras do discurso lavajatista, dez anos antes do início da Operação Lava Jato. Para ele, a operação italiana "constituiu uma das mais exitosas cruzadas judiciárias contra a corrupção política e administrativa" (Moro, 2004, p. 60, grifo nosso), combinando "virtuosamente" prisões, pré-julgamento como "forma de destacar a seriedade do crime", delações premiadas/confissões e publicidade. A opinião pública pode, inclusive, "impor alguma espécie de punição a agentes públicos corruptos, condenando-os ao ostracismo" (Moro, 2004, p. 61).

Em seu texto de 2004, Moro afirma que haveria condições institucionais para a realização de uma operação judicial semelhante no Brasil. De acordo com ele, teria que ser modificada uma prática judicial pouco rigorosa contra a corrupção, "que permite tratar com maior rigor processual um pequeno traficante de entorpecente (por exemplo, as denominadas 'mulas') do que qualquer acusado por crime de 'colarinho branco', mesmo aquele responsável por danos milionários à sociedade" (Moro, 2004, p. 61).

Moro empreende um exercício de revisionismo histórico acerca dos desdobramentos da implosão do sistema político, ocorrida em função da Mãos Limpas, que, visto a posteriori, ajuda a explicar a emergência de Bolsonaro. Ele relativiza a emergência de Silvio Berlusconi enquanto resultado daquele processo, como se os dois eventos - a implosão do sistema político e a ascensão de Berlusconi - fossem desprovidos de nexo causal, partes de um mesmo todo.

A experiência do caso italiano sustenta uma visão jurídica que orienta discursos e ações do caso brasileiro. A operação Mãos Limpas e a depuração da corrupção são o futuro que o Brasil deveria perseguir. Moro não nega que 
a Operação Mãos Limpas tenha reconfigurado o quadro político na Itália, mas minimiza o fato, isto é, o relativiza.

De acordo com dados disponibilizados por Fábio Kerche, entre 1992 e 1994, os cinco partidos políticos italianos mais importantes declinaram de votos e apoio. Emerge deste contexto a figura política de Silvio Berlusconi, então o homem mais rico da Itália, dono de vários veículos de comunicação e neófito na política. Ele cria um partido de centro-direita, Forza Itália, para depois se tornar primeiro-ministro do país (Kerche, 2018, p. 256).

Mas, para Moro, a ascensão de Berlusconi é vista como um paradoxo, nada mais: "tendo ou não Berlusconi alguma responsabilidade criminal, não deixa de ser um paradoxo que ele tenha atingido tal posição [de ser Primeiro Ministro] na Itália mesmo após a operação mani pulite” (Moro, 2004, p. 60). Para o ex-juiz, ainda, a "ação judicial contra a corrupção só se mostra eficaz com o apoio da democracia”, isto é, "é a opinião pública esclarecida que pode, pelos meios institucionais próprios, atacar as causas estruturais da corrupção" (Moro, 2004, p. 61, grifo nosso). Na linha argumentativa de Moro, Berlusconi é um efeito imprevisto e desencaixado em relação ao processo maior de combate à corrupção. Um efeito colateral e não uma consequência. Aliás, a alienação às consequências dos próprios atos parece ser uma das premissas da lógica da transparência atualista.

Segundo Pereira, Araujo e Marques (2020, pp. 200-201), “o desejo por transparência total é um dos traços perversos da era digital" e "o escândalo do The Intercept mostrou que o discurso da transparência é um cheque em branco que só vale quando usado a favor do ex-juiz. Na cozinha da Lava Jato, a intransparência foi a regra". Para os autores,

o funcionamento da Lava Jato não é muito diferente do funcionamento da Google e dos capitalistas da vigilância. Eles pedem um acesso ilimitado à sua privacidade, à sua vida íntima, aos seus dados, ao seu telefone, ao seu celular, com a promessa de que isso vai resolver inúmeros problemas, vai acabar com a corrupção, e terminam, na verdade, construindo grandes estruturas de poder e manipulação com as informações que reúnem. 


\section{III}

Levando em conta a prerrogativa da negação da política, como tática permanente para o combate à corrupção e o estabelecimento de uma agenda para o país, identificamos - a partir do texto de 2004 e de avaliações de Moro sobre o lugar da Operação Lava Jato - a edificação de um programa jurídico-político de Moro, estruturado na existência de três passos fundamentais.

O primeiro passo seria o ativismo judicial para o enfretamento do problema da corrupção, considerando uma determinada maneira de compreendê-la como fenômeno estrutural da formação social brasileira. Confere-se ao sistema judiciário protagonismo para conduzir as transformações estruturais implicadas no combate à corrupção, admitindo, portanto, a possibilidade de que o magistrado possa extrapolar sua missão constitucional de aplicar a lei.

Segundo Alexandre Santos de Moraes (2020), esse padrão de reivindicação missionária e atuação do judiciário tem início na ação penal 470, conhecida como caso do Mensalão. "Observou-se não apenas o avanço de um processo de estetização e espetacularização do processo penal, mas também a celebração dos juízes como agentes moralizadores que cumprem o papel de corrigir os rumos que os demais poderes se mostravam supostamente incapazes de resolver" (Moraes, 2020, p. 291). O autor destaca, como exemplo, a defesa de Luis Roberto Barroso em relação à necessidade dos juízes considerarem os "sentimentos sociais" e os fatores extrajudiciais capazes de repercutir o julgamento, gerando um grave problema para o funcionamento da democracia:

na perspectiva de Barroso, a valorização da opinião pública parece acenar para a necessidade de aproximar o Poder Judiciário de uma prática política que não está sob sua alçada, para o resguardo da própria democracia. Cria-se, através desse artifício, a ilusão de que o Judiciário faz política em termos semelhantes aos poderes que tem seus representantes escolhidos pelo voto popular, contrariando o caráter contra majoritário que está nos alicerces de sua raison d'être. (Moraes, 2020, p. 294)

Em termos semelhantes aos propostos por Barroso, a reivindicação do ativismo judicial atravessa a perspectiva jurídica manifestada nos trabalhos acadêmicos de Sergio Moro. Barroso é aqui simbolicamente tomado por nós como uma espécie de alter-ego de Moro. Conforme pesquisa realizada por 
Francisco Hayashi (2020) a partir da Dissertação de Mestrado, da Tese de Doutorado, de artigos e de um livro autoral escritos por Moro, há uma persistente defesa de "sensibilização do judiciário em relação às temáticas sociais, efeitos pedagógicos da postura judicial ativa, mesmo reconhecendo os limites da falta de capacidade do juiz desempenhar políticas complexas" (Hayashi, 2020, p. 5), afirmando, ainda, a centralidade do ativismo judicial com poderes para ordenar a implementação de políticas públicas, sensível às necessidades de sua época.

No artigo “A missão do STF”, publicado na revista Veja em 2018, Moro afirma que, "considerando o grau de deterioração da coisa pública, revelado no mensalão e na Operação Lava Jato, não deixa de ser justificado algum ativismo judicial contra a corrupção" (Moro, 2018). No ano seguinte, avaliando os avanços da operação, Sergio Moro atribui a ela um feito histórico e, por que não dizer, revolucionário: a quebra na tradição de impunidade para a grande corrupção (Moro, 2019, p. 236). O objeto da Lava Jato extrapola, portanto, sua prerrogativa jurídico-investigativa, mirando um horizonte mais amplo: a definição da agenda nacional nos próximos anos. A partir dela, a "corrupção, sua prevenção e seu enfrentamento ingressaram definitivamente na agenda pública brasileira, o que influenciará o debate político nos anos que virão (Moro, 2018, p. 257).

Neste ponto reside o segundo passo do programa jurídico-político de Moro: o ativismo judicial levará a Lava Jato ao estatuto de movimento político-social de uma época - já não se trata mais, apenas, de uma Força-Tarefa jurídico-investigativa. Ela entoa a voz dos cidadãos indignados com a corrupção, o maior dos nossos males, a partir de uma compreensão específica: a corrupção sistêmica se estrutura no patrimonialismo e na presença onipotente do Estado nas relações sociais.

A esse respeito, Moro afirma, em entrevista ao programa Roda Viva, em 2018: "a Lava Jato não é uma conquista apenas de juízes, mas dos milhões de brasileiros que saíram em 2016 às ruas protestando contra a corrupção.” (Moro, 2018b). Na mesma direção, sugere, em artigo de 2018, que o aspecto mais negativo da Lava Jato não estava nela propriamente, mas no sistema político: "a relativa inércia da maioria das lideranças políticas brasileiras, dos partidos políticos e dos demais poderes da República em relação ao quadro de corrupção sistêmica descoberto, evidenciada na ausência de aprovação de reformas 
mais abrangentes que pudessem diminuir incentivos e oportunidades de corrupção” (Moro, 2019, p. 256).

Anos antes, em "Caminhos para reduzir a corrupção", publicado no jornal O Globo em outubro de 2015, o então juiz federal propõe medidas para enfrentamento do pagamento de propina sobre contratos públicos. Nos termos do autor, enquanto "regra do jogo", "compromisso endêmico”, “obrigação consentida entre os participantes", praticada por agentes públicos no trato do Estado, a propina deve ser encarada como "mal a ser combatido por todos" (Moro, 2015). A Lava Jato se apresenta, assim, como bandeira empunhada por uma época; uma causa, liderada pelo grupo de Curitiba, mas não encerrada ali. Movida por um senso de urgência histórica, a força-tarefa, em particular, e o poder judiciário como um todo, representariam a vanguarda de um movimento político mais amplo. O combate à corrupção seguia uma marcha inexorável, impossível de ser contida, cabendo aos heróis revolucionários do judiciário mobilizar a sociedade para a ação.

Os tempos atuais oferecem uma oportunidade de mudança, o que exige a adoção, pela iniciativa privada e pela sociedade civil organizada, de uma posição de repúdio à propina, e, pelo Poder Público, de iniciativas concretas e reais, algum ativismo é bem-vindo, para a reforma e o fortalecimento de nossas instituições contra a corrupção. Milhões já foram às ruas protestar contra a corrupção, mas não surgiram respostas institucionais relevantes. O tempo está passando e o momento, em parte, está sendo perdido (Moro, 2015).

O diagnóstico é o seguinte: a politização ocasionada pelo controle estatal em empresas como a Petrobrás pavimenta o caminho para a corrupção, pois facilita a barganha de agentes públicos na negociação dos contratos. A empresa pública se torna objeto de loteamento político e potencialmente passível de práticas corruptas. Como consequência, ainda no texto de 2015, nos termos de Moro, "a economia perde eficiência" e "perde-se a racionalidade na gestão pública”. Ou seja, a propina justifica o excesso de gastos, propiciada pela combinação entre centralização política e econômica implicada na gestão das empresas estatais. Moro dialoga, desta maneira, com o repertório ideológico fundado na razão neoliberal, partindo do princípio de que, quanto mais a economia conseguisse caminhar por uma trilha despolitizada, tanto mais ela 
seria racional e eficiente. A administração da Petrobrás deveria ser desprovida de interesse político.

Esta perspectiva fica ainda mais evidente na análise de Luis Roberto Barroso, já Ministro do STF - publicamente entusiasta defensor do discurso lavajatista - acerca do instinto de urgência histórica surgido no seio da Lava Jato, em artigo oportunamente intitulado "Empurrando a história: corrupção, mudança de paradigmas e refundação do Brasil” (Barroso, 2019). Valendo-se, de maneira muito particular, da conhecida formulação de Raymundo Faoro, Barroso afirma que a onipresença do Estado nas relações sociais e o patrimonialismo estariam dentre as origens e causas remotas da corrupção (Barroso, 2019 p. 6). Para ele, desde o período colonial, o patrimonialismo decorrente da colonização ibérica distinguiu a formação social brasileira, marcada pela má separação entre esfera pública e privada - "a Fazenda do rei e a Fazenda do reino - o rei era sócio dos colonizadores -, e as obrigações privadas e os deveres públicos se sobrepunham" (Barroso, 2019 p. 6).

Como desdobramento negativo de longa duração, há uma cultura de paternalismo e compadrio em torno do Estado, acima do mérito e da virtude; em suas palavras, "uma onipresença do Estado, que exerce o controle da política e das atividades econômicas, pela exploração direta ou por mecanismos de financiamento a empresas privadas e de concessão de benefícios. A sociedade torna-se dependente do Estado para quase tudo o que é importante, sejam projetos pessoais, sociais ou empresariais” (Barroso, 2019, p. 7).

Para Rodrigo Perez Oliveira, essa concepção de corrupção, amplamente disseminada na crise democrática brasileira iniciada em junho de 2013, está ancorada em uma gramática de esvaziamento do lugar do Estado e de valorização de virtudes disseminadas pelo repertório liberal (Oliveira, 2018). Neste sentido, honestidade e corrupção se apresentariam como atributos de ação individual, cabendo ao "Estado Liberal apenas o planejamento e a execução de medidas que permitissem aos indivíduos atingirem, usando seus próprios meios, os seus objetivos individuais" (Oliveira, 2018, p. 393).

Ainda que não tenha surgido no contexto político recente, este dispositivo discursivo liberal antiestatista tornou-se uma ferramenta política poderosa no curso da crise, na medida em que construiu uma relação necessária entre excesso de Estado e corrupção. Compreendida como movimento político e expressão de clamor social por mais honestidade e punição, a Lava Jato, tal 
como delineada por Sergio Moro e Luis Roberto Barroso, representa o instrumento mais vigoroso na difusão de valores associados à negação da política, à "despolitização" da economia, às críticas ao excesso de Estado. Combinado aos esforços por maior racionalização e eficiência na obtenção de resultados mais lucrativos, tal discurso entoa e acomoda a propagação de uma agenda para o país calcada na razão neoliberal. Como desdobramento, atinge mais intensamente o Partido dos Trabalhadores e os projetos situados à esquerda no espectro ideológico, já que estes advogam pela centralidade do Estado como indutor do desenvolvimento econômico e instância capaz de diminuir as desigualdades sociais.

Terceiro passo do programa jurídico-político manifestado por Moro: reivindicação de uma super autonomia das instituições judiciais envolvidas nas investigações da Lava Jato, sem qualquer tipo de regulação institucional externa. Uma autonomia que permitisse à força-tarefa atuar em uma condição privilegiada: agir politicamente protegida, em uma redoma de despolitização; ora se abrindo às manifestações da opinião pública que correspondessem a seus anseios, ora se fechando a críticos e interferências externas de políticos profissionais - taxados como condescendentes com a corrupção.

Quando disserta sobre as condições que viabilizaram a Operação Mani Pulite, Moro destaca o princípio de autonomia plena capaz de promover um ativismo judicial que se pusesse em confronto com a política: "independência judiciária, interna e externa, a progressiva deslegitimação de um sistema político corrupto e a maior legitimação da magistratura em relação aos políticos profissionais" (Moro, 2004, p. 58). Diante da superioridade moral do judiciário lavajatista, e negando aos políticos a possibilidade de promover o bem comum da sociedade, este princípio de autonomia, levado ao limite, romperia com o sistema de freios e contrapesos previsto na divisão de poderes da República. Concentra-se o poder de decisão nas mãos dos juízes - vistos como heróis revolucionários - como se eles não fossem passíveis a decisões imprecisas, a espírito de proteção corporativista ou, até mesmo, como se não pudessem sucumbir à tirania, ao não enxergarem limitação no próprio poder.

Para Fábio Kerche, a Operação Mãos Limpas ofereceu mais do que uma inspiração aos juízes e promotores da Lava Jato. Ela ganhou maiores dimensões quando o sistema judicial brasileiro se aproximou, na prática, do modelo italiano, unificando todas as etapas do processo criminal - investigação, acusação 
e julgamento - em uma mesma instância capaz de operar em cooperação (Kerche, 2018, p. 259). Se, por um lado, tal unificação diminuía tempo e custos operacionais acarretados na mobilização de instituições diversas, por outro, a inexistência de uma clara divisão de tarefas e o esforço de parceria diluiria a distinção entre as ações da Polícia Federal, do Ministério Público e dos juízes (Kerche, 2018, p. 273) - as mensagens divulgadas pela Vaza Jato evidenciam este problema, revelando situações em que o então juiz Sergio Moro orientava procedimentos para a acusação que, mais tarde, ele mesmo viria a julgar. Deste modo, no caso italiano - e, também, no brasileiro - "a acusação tem significativa vantagem em relação à defesa em um processo criminal" (Kerche, 2018, p. 273), indo ao encontro da percepção pública mais disseminada de que a justiça se cumpre por meio da condenação.

A Lava Jato extrapolou a autonomia proposta na Carta de 1988, devido a mudanças na legislação ocorridas durante os governos petistas. A "Lei da delação Premiada" (Lei 12.850/13), por exemplo, autorizava promotores do Ministério Público a negociar, sem interferência de um magistrado, penas menores para um acusado em troca de denúncias de supostos comparsas dos esquemas fraudulentos. As prisões, por sua vez, serviram como instrumento de negociação com acusados, incentivando delações premiadas e inclusão de novos suspeitos (Kerche, 2018, p. 280).

Em “Independência judicial e abuso de autoridade”, artigo publicado n'O Globo em abril de 2017, Sergio Moro exalta a super autonomia do judiciário, posta em prática na Operação Lava Jato. “As Cortes de Justiça precisam ser independentes. Necessário assegurar que os julgamentos estejam vinculados apenas às leis e às provas e que sejam insensíveis a interesses especiais ou à influência dos poderosos" (Moro, 2017). A defesa da autonomia era acompanhada de ataque à chamada "lei de abuso de autoridade", então proposta no Senado por Renan Calheiros e Roberto Requião, entendida como contra-ataque dos poderosos da política. A iniciativa do Legislativo em oferecer algum grau de contraponto externo às decisões tomadas pelo judiciário lavajatista é vista como ameaça ou vingança. Nas palavras de Moro, "na prática, submete policiais, promotores e juízes à vingança privada proveniente de criminosos poderosos.”.

Causa certa surpresa o momento da deliberação, quando da divulgação de diversos escândalos de corrupção envolvendo elevadas autoridades políticas e, portanto, oportunidade na qual nunca se fez mais necessária a independência da magis- 
tratura, para que esta, baseada apenas na lei e nas provas, possa determinar, de maneira independente e sem a pressão decorrente de interesses especiais, as responsabilidades dos envolvidos, separando os culpados dos inocentes (Moro, 2017).

A reivindicação de autonomia discricionária impõe um problema ao funcionamento do modelo democrático-representativo no que tange à questão da soberania. Afinal, a negação e a criminalização da política destituem de poder (ou criminalizam) aquele que, no processo eleitoral, é escolhido pelo povo como seu representante, evidenciando uma tensão, exposta pela crise, entre soberania e controle político (Avritzer; Marona, 2017, p. 360). A proliferação de canais extraparlamentares de representação formal e informal (participação-em-espaços-participativos) - como as iniciativas populares de projetos de lei por meio de abaixo-assinados - enfraqueceu a ideia de governo representativo e, ao mesmo tempo,

deu asas à pretensão das fortalecidas instituições judiciais (do Poder Judiciário e, particularmente, do Ministério Público) de, ao mediar a cidadania, disputar a representação do interesse público, o que, em um cenário de desvelamento, controle e combate crescentes da corrupção, estabeleceu um quadro de petrorianismo judicial que traz severas máculas à democracia brasileira (Avritzer; Marona, 2017, p. 363).

Eis um dos resultados mais expressivos do discurso e da ação política lavajatista, protagonista da crise da democracia brasileira entre 2014-2020: fundando-se no princípio de super autonomia sem regulação, acaba por enfraquecer a soberania, abrindo caminho para todo tipo de seletividade e perseguição política.

\section{V}

Do ponto de vista conceitual, gostaríamos de acrescentar, ao final de nossa reflexão, que, mesmo trabalhando com as distinções entre negação, negacionismo e revisionismo de Pereira (2015), a pesquisa nos levou à conclusão de que, apesar de serem fenômenos distintos, eles se sobrepõem, se interconectam, se entrecruzam e se interpõem constantemente. Tratam-se, portanto, 
de fenômenos dinâmicos e de difícil distinção quando confrontados com a realidade do passado histórico. Ao mesmo tempo, como esperamos ter mostrado, são, antes de tudo, fenômenos políticos. Para deixarmos mais claro esse ponto é preciso, ainda, analisarmos mais detidamente como o ativismo judicial de Moro atualiza e, paradoxalmente, nega dimensões de uma figura política histórica: o herói revolucionário.

O que significa ativismo judicial nos textos e discursos de Moro? Do nosso ponto de vista, é uma reivindicação e legitimação de que os magistrados ocupem um papel que extrapole a mera aplicação da lei, servindo como instrumento para o estabelecimento de uma guerra contra os políticos profissionais e, como desdobramento, uma negação da política. $\mathrm{O}$ ativismo aponta na direção de uma agenda para o país, identificando, no protagonismo estatal, a mola mestra causadora da corrupção endêmica, a partir de uma leitura muito específica da ideia de patrimonialismo em Raymundo Faoro. Por outro lado, é também a reivindicação de uma autonomia para a ação discricionária do poder judiciário, que não envolva fiscalização, freio ou contrapeso por parte dos outros poderes da República - já que ele é considerado o único poder capaz de garantir a transparência sincera e verdadeira da vida pública.

Como resultado, além do estabelecimento de uma condição privilegiada de atuação do poder judiciário sem contraste, o procedimento implicou, entre 2014-2020, em um problema de soberania, na medida em que o super ativismo judicial envolvendo casos de combate à corrupção não se ancora na delegação de poder e representação estabelecida nos termos da democracia liberal representativa. Em outras palavras, em nome de quem e por meio de qual pacto representativo o juiz atua quando extrapola a sua função de aplicar a lei, investindo-se da condição do herói na cruzada contra a corrupção?

Ou seja, além do risco da tirania judiciária sem freio e contrapeso, a soberania popular, nas reflexões de Moro, é a todo o tempo ameaçada, pois o representante eleito para legislar é substituído pelo magistrado que, além de não precisar negociar com a sociedade a sua agenda em um processo eleitoral, se vê desobrigado a pactuar com pares igualmente eleitos - como ocorre no jogo legislativo - para formar consensos ou maiorias capazes de estabelecer medidas estruturais de combate à corrupção.

Deste modo, atuando no interior da estabilidade institucional do modelo democrático liberal-representativo e pela despolitização do poder judiciário 
produzida no interior dos governos petistas, a Operação Lava Jato e a sua aposta na tirania da percepção e na ativação contínua de escândalos políticos, movidos pelo princípio da transparência atualista, assentou as condições de possibilidade para a operacionalização do "negacionismo enquanto tática política" (Cf. Valim; Avelar, 2020), traço constitutivo e permanente do bolsonarismo.

Cabe ressaltar que, na Presidência, Bolsonaro tem atuado para que não se cumpra a promessa lavajista de enfrentamento permanente da corrução sistêmica. Promessa que, no limite, é efetivamente inexequível: a inexistência de um sistema democrático estável impossibilita, de antemão, o combate efetivo e permanente à corrupção. Bolsonaro tem atuado para "virar a página" e encerrar a experiência lavajatista às circunstâncias da crise que retirou o Partido dos Trabalhadores do poder e implodiu o sistema político forjado na redemocratização da década de 1980. Bolsonaro atualiza ${ }^{6}$ e encerra ${ }^{7}$ a Lava Jato às circunstâncias anteriores a seu governo, deixando-a sem elo de continuidade com o presente. Sujeitada ao personalismo/heroismo de seus protagonistas, Sergio Moro e Deltan Dallagnol, afastados de suas atribuições na Operação, ela se tornou presa fácil às tentativas de aparelhamento político das instituições judiciárias levadas a cabo por Bolsonaro. Para Jair Messias Bolsonaro, o maior legado da Lava Jato é a ascensão dele mesmo como mito.

Destaca-se que o registro e a publicização da negação utilizados pela Operação Lava Jato não são o mesmo que a negação bolsonarista. Tal negação opera fundamentalmente às margens da grande mídia, partindo de um centro difuso em torno das redes sociais e do aplicativo WhatsApp, por meio de massas digitais, construindo uma identidade política “outsider" em relação à chamada, por bolsonaristas e lavajatistas, de velha política tradicional. Já o lavajatismo utilizou, sobretudo, instrumentos convencionais de mobilização, como as grandes empresas de comunicação, mantendo a opinião pública em compasso de permanente atualização a partir da espetacularização das ações do judiciário (Cf., entre outros, Pinha, 2020; Singer, 2018). Enquanto a modalidade bolsonarista de negação sugere uma aversão ao efeito de verdade canalizado pelos grandes veículos de comunicação convencional, a Lava Jato emoldura toda a sua narrativa a partir da grande mídia, contando, ainda, com a multiplicação dos efeitos vindos da internet. Tal multiplicação de efeitos sugere uma contínua atualização, mobilização do público e radical abertura para 
que as decisões jurídicas correspondam aos anseios "da opinião pública esclarecida" (Moro, 2004, p. 61, grifo nosso).

Em nome de uma cruzada moral de combate à corrupção, envolvendo problemas de desvio de competência, constrangimento das relações entre autonomia do judiciário e soberania popular, ampliação do escopo de atuação do juiz enquanto herói revolucionário monopolizador de virtudes morais, a Lava Jato produziu e operou com um tipo particular de negação da política, que se traduziu numa forma de intervenção na política movida pela opinião pública, por meio da produção dos escândalos canalizada pelos grandes meios de comunicação em constante atualização. Assim, seguindo a analogia entre a história da Lava Jato e uma ideia liberal de Revolução sugerida por Lynch $(2018)^{8}$, podemos dizer que Moro atualiza o heroísmo da sinceridade.

Para Henrique Estrada Rodrigues (2021), certa interpretação de Rousseau, sobretudo entre os jacobinos, opera com a dicotomia entre transparência (natureza, pureza, verdade) e opacidade (política, teatro, cultura, corrupção) para fundamentar a ação do heroísmo da sinceridade/transparência. Moro, assim, é o juiz que julga no tribunal revolucionário (Lava Jato) a fim de revelar a verdadeira face das mazelas da República corrompida. O herói da transparência, deste modo, é o da pureza ideológica e de ações desprovidas de interesses políticos. Já os inimigos são corruptos e agem de forma mascarada, velada e dissimulada. O heroísmo revolucionário, como sugere Rodrigues (2021), é uma concepção heroica do político e do ator revolucionário. O risco é a desmedida, na transformação de si próprio como um exemplo a ser seguido. Um humano para além da condição humana, já que superior à maioria dos mortais. As dimensões próprias do político, isto é, a pluralidade e a igualdade, por exemplo, escapam assim das contradições dessa forma de agir no mundo entre os diferentes.

Teria sido possível preservar a dimensão política do herói Moro? Sim. Desde que estivesse poupado do risco da Hybris, sua maldição. Como os jacobinos, ele parece ter se perdido na Hybris e, em especial, na negação da dimensão política do heroísmo. Afinal, como também salienta Rodrigues, o princípio da transparência como atributo pessoal e de grupo muito facilmente escapa do político por moralizá-lo a partir da ação exemplar. Em outras palavras, tendo em vista as relações entre as dimensões heroicas do político e políticas do herói, percebemos, em nossa análise, que o negacionismo de Sergio Moro pode ser 
percebido justamente na tentativa de negar, esconder, distorcer, dissimular e embaralhar a dimensão política do herói por meio da "retórica da técnica" (Silveira, 2020). A esse respeito é exemplar que Moro tenha afirmado, quando se tornou Ministro de Bolsonaro, que não estava "ingressando na política como um político verdadeiro", já que seu cargo seria “técnico" (Silveira, 2020, p. 215).

Além disso, a negação do político e da política passou entre 2014-2020, sobretudo, como vimos, pela moralização do político e da política se utilizando, em especial, da dimensão retórica da transparência atualista. Afinal, por mais que seja difícil definir a política e o político, de algumas coisas sabemos: essas instâncias não se definem e não se operam pelas dimensões da moral. Como destaca, também, Rodrigues (2021), o espaço da política e do político não é o espaço da autofiguração de modelos de conduta que querem modelar o mundo.

O escândalo da Vaza Jato mostrou o quanto esse heroísmo da transparência precisa das instâncias sombrias, impuras, opacas e obscuras para agir e se comunicar, inclusive, com ministros do STF. Afinal, eles tentaram agir a partir das lógicas do segredo, do bastidor, da opacidade, da manipulação e, em especial, de uma palavra que é uma das ações humanas que permeiam e fundamentam a base das questões aqui pensadas: a mentira.

Atualização de última hora: enquanto fazíamos os últimos ajustes gramaticais e de formatação do nosso artigo, após o retorno dos pareceristas, assistimos à anulação monocrática das condenações de Lula pelo ministro do STF, Edson Fachin, o que representou a devolução dos direitos políticos do ex-presidente. No dia seguinte, em 16/03/2021, o Supremo Tribunal Federal pautou, por meio da sua segunda turma, a retomada do julgamento da parcialidade do ex-juiz Sérgio Moro em relação às suas decisões na Operação Lava Jato, após o exame das conversas divulgadas pelo The Intercept Brasil entre Moro e Procuradores da Força-Tarefa. Neste dia, os Ministros Gilmar Mendes e Ricardo Lewandowski votaram a favor da parcialidade de Moro e, depois, o julgamento precisou ser suspenso devido ao pedido de vistas do Ministro Kassio Marques. O Ministro Mendes afirmou, dentre outras coisas importantes, que a conduta de Moro à frente da Operação Lava Jato, apoiada em considerável medida pela grande imprensa, foi pautada por tentativas de retirar o ex-presidente Lula da eleição de 2018, e tal fato significa que o ex-juiz foi protagonista do maior escândalo judicial da história do Brasil. 


\section{REFERÊNCIAS}

AARÃO REIS, Daniel. Notas para a compreensão do Bolsonarismo. Estudos Ibero-Americanos, Porto Alegre, v. 46, n. 1, pp. 1-11, 2020.

ALESSI, Gil. Professor da FGV: "Os procuradores não têm obrigação de ser imparciais, o Judiciário sim”. 19 set. 2016. Disponível em: http://brasil.elpais.com/brasil/2016/09/19/politica/1474312121_439643.html. Acesso em: 20 set. 2020.

AVRITZER, Leonardo. Impasses da democracia no Brasil. Rio de Janeiro: Civilização Brasileira, 2016.

AVRITZER, Leonardo; MARONA, Marjorie. A Tensão entre Soberania e Instituições de Controle na Democracia Brasileira. Dados, vol. 60, n. 2, pp. 359-393, 2017.

AVRITZER, Leonardo. Política e antipolítica: A crise do governo Bolsonaro. São Paulo: Todavia, 2020.

BARROSO, Luis Roberto. Empurrando a história: combate à corrupção, mudança de paradigmas e refundação do Brasil. In: PINOTTI, Maria Cristina (Org.). Corrupção: Lava Jato e Mãos Limpas. São Paulo: Portfolio Penguin, 2019. pp. 9-19.

BAUER, Caroline Silveira. Usos do passado da ditadura brasileira em manifestações públicas de Jair Bolsonaro. In: KLEM, Bruna Stutz; PEREIRA, Mateus; ARAUJO, Valdei. (Orgs.). Do fake ao fato: (des)atualizando Bolsonaro. Vitória: MilFontes, 2020. pp. 173-194.

BAUER, Caroline Silveira; NICOLAZZI, Fernando Felizardo. O historiador e o falsário: Usos públicos do passado e alguns marcos da cultura histórica contemporânea. Varia hist., Belo Horizonte, v. 32, n. 60, pp. 807-835, 2016.

FUJITA, Gabriela; MARCHAO, Talita. 78\% dos brasileiros dizem sentir aumento da corrupção, diz Transparência Internacional. 9 out. 2017. Disponível em: https:// noticias.uol.com.br/internacional/ultimas-noticias/2017/10/09/78-dos-brasileiros-dizem-sentir-aumento-da-corrupcao-diz-transparencia-internacional.htm. Acesso em: 5 jan. 2021.

HAN, Byung-Chul. No enxame: reflexões sobre o digital. Trad. Miguel Serras Pereira. Lisboa: Relógio D’Água, 2016.

HAN, Byung-Chul. A sociedade da transparência. Trad. Miguel Serras Pereira. Lisboa: Relógio D’água, 2014.

HAYASHI, Francisco Yukio. Pensamento jurídico de Sérgio Moro: uma revisão bibliográfica. 2020. Disponível em: https://www.researchgate.net/publication/340933495_Pensamento_juridico_de_Sergio_Moro_uma_revisao_bibliografica. Acesso em: 02 nov. 2020.

KERCHE, Fábio. Ministério Público, Lava Jato e Mãos Limpas: uma abordagem institucional. Lua Nova, n. 105, pp. 255-286, 2018.

KOSELLECK, Reinhart. Estratos do tempo. Estudos sobre História. Rio de Janeiro: Contraponto: PUC-Rio, 2014. 
LYNCH, Christian. A Revolução Judiciarista e as linhagens do pensamento brasileiro. Folha de São Paulo, São Paulo, p. A3, 11 mai. 2018.

MENESES, Sônia. Bolsonarismo: um problema "de verdade" para a história. In: KLEM, Bruna Stutz; PEREIRA, Mateus; ARAUJO, Valdei. (Orgs.). Do fake ao fato: (des) atualizando Bolsonaro. Vitória: MilFontes, 2020. pp. 33-46.

MORAES, Alexandre Santos de. Ensaio sobre os usos da opinião pública no país da supremocracia. In: OLIVEIRA, Rodrigo Perez; SILVA, Daniel Pinha (Orgs.). Tempos de crise: ensaios de história política. Rio de Janeiro: Autografia, 2020. pp. 281-336.

MORO, Sergio Fernando. Considerações sobre a Operação Mani Pulite. Revista CEJ, Brasília, v. 26, pp. 56-62, 2004.

MORO, Sergio Fernando. Artigo: Independência judicial e abuso de autoridade, por Sergio Moro. 25 abr. 2017. Disponível em: https://oglobo.globo.com/brasil/artigo-independencia-judicial-abuso-de-autoridade-por-sergio-moro-21251404. Acesso em: 01 nov. 2020.

MORO, Sergio Fernando. Artigo: Caminhos para reduzir a corrupção, por Sergio Moro. 4 out. 2015. Disponível em: https://oglobo.globo.com/brasil/artigo-caminhos-para-reduzir-corrupcao-por-sergio-moro-17684788. Acesso em: 1 nov. 2020.

MORO, Sergio. Sobre a Operação Lava Jato. In: PINOTTI, Maria Cristina (Org.). Corrupção: Lava Jato e Mãos Limpas. São Paulo: Portfolio Penguin, 2019. pp. 184-216.

MORO, Sergio. A missão do STF. Veja, São Paulo, pp. 80-81, 24 set. 2018.

MORO, Sergio. Entrevista ao Roda Viva. 89 min. 42 seg. 26 mar. 2018b. Disponível em: https://www.youtube.com/watch?v=DqtPZVBhfNw\&list=LLr5lqf4Xq6Z4Ktg TaH9xalQ\&index=259. Acesso em: 18 nov. 2020.

NOBRE, Marcos. Ponto-final: A guerra de Bolsonaro contra a democracia. São Paulo: Todavia, 2020.

OLIVEIRA, Rodrigo Perez. O significado do conceito "corrupção" na semântica política da crise brasileira (2013-2016). Anos 90, Porto Alegre, v. 25, n. 48, pp. 379-408, 2018.

PEREIRA, Mateus Henrique de Faria; ARAUJO, Valdei Lopes de. Atualismo 1.0: como a ideia de atualização mudou o século XXI. Vitória: Milfontes, 2018.

PEREIRA, Mateus Henrique de Faria. Nova direita? Guerras de memória em tempos de Comissão da Verdade (2012-2014). Varia hist., vol. 31, n. 57, pp. 863-902, 2015.

PEREIRA, Mateus H. F.; ARAUJO, Valdei. Vozes sobre Bolsonaro: esquerda e direita em tempo atualista. In: KLEM, Bruna Stutz; PEREIRA, Mateus; ARAUJO, Valdei. (Orgs.). Do fake ao fato: (des)atualizando Bolsonaro. Vitória: MilFontes, 2020. pp. 115-140.

PEREIRA, Mateus Henrique de Faria; MARQUES, Mayra de Souza; ARAUJO, Valdei Lopes. Almanaque da COVID-19: 150 dias para não esquecer ou a história do encontro entre um presidente fake e um vírus real. Vitória: Milfontes, 2020. 306 p. 
PINHA, Daniel. A ascensão do mito: tela e moldura do discurso bolsonarista em tempos de crise democrática. In: OLIVEIRA, Rodrigo Perez; SILVA, Daniel Pinha (Orgs.). Tempos de crise: ensaios de história política. Rio de Janeiro: Autografia, 2020. pp. 337-378.

RODRIGUES, Henrique Estrada. Thomas More e a utopia indisciplinada. Podcast inédito que será vinculado no programa da ANPUH historiador/historiadora explica no primeiro semestre de 2021. $15 \mathrm{~min}$. Será disponibilizado em: https://sound cloud.com/anpuh/sets/historiador-explica.

RODAS, Sergio. Moro reconhece erro em grampo de Dilma e Lula, mas mantém gravação. 17 mar. 2016. Disponível em: https://www.conjur.com.br/2016-mar-17/ moro-reconhece-erro-grampo-dilma-lula-nao-recua. Acesso em: 10 out. 2020.

ROSANVALLON, Pierre. Le siècle du populisme. Histoire, théorie, critique. Paris: Seuil, 2020.

SILVA, Daniel Pinha. A longa noite de 64: Bolsonaro e a experiência democrática vista do Parlamento. In: KLEM, Bruna Stutz; PEREIRA, Mateus; ARAUJO, Valdei. (Orgs.). Do fake ao fato: (des)atualizando Bolsonaro. Vitória: MilFontes, 2020. pp. 195-231.

SILVEIRA, Mariana de Moraes. Juristas e vida pública no Brasil: trajetórias no tempo. In: KLEM, Bruna Stutz; PEREIRA, Mateus; ARAUJO, Valdei. (Orgs.). Do fake ao fato: (des)atualizando Bolsonaro. Vitória: MilFontes, 2020. pp. 225-238.

SIMMEL, George. A sociologia do segredo e das sociedades secretas. Tradução de Simone Carneiro Maldonado. Revista de Ciências Humanas, Florianópolis: EDUFSC, vol. 43, n. 1, pp. 219-242, 2009.

SINGER, André. O lulismo em crise: um quebra-cabeça do período Dilma (2011-2016). São Paulo: Companhia das Letras, 2018.

THE INTERCEPT BRASIL. Leia todas as reportagens que o Intercept e parceiros produziram para a Vaza Jato. 20 jan. 2020. Disponível em: https://theintercept. com/2020/01/20/linha-do-tempo-vaza-jato/. Acesso em: 9 jan. 2021.

THOMPSON, John B. Fronteiras cambiantes da vida pública e privada. MATRIZes, ano 4, n. 1, pp. 11-36, 2010.

TRANSPARÊNCIA INTERNACIONAL. Disponível em: https://pt.wikipedia.org/wiki/ Transpar\%C3\%AAncia_Internacional. Acesso em: 11 mar. 2021.

TRAVERSO, Enzo. Revisão e Revisionismo. In: SENA JUNIOR, Carlos Zacarias de; MELO, Demian Bezerra de; CALIL, Gilberto Grassi (Orgs.). Contribuição à crítica da historiografia revisionista. Rio de Janeiro: Consequência Editora, 2017. pp. 27-37.

TRUCKER, Aviezer. Historiographic Revision and Revisionism: The Evidential Difference. In: KOPECEK, Michal (Ed.). Past in the Making: Historical Revisionism in Central Europe after 1989. Budapest: CEU Press, 2007. pp. 1-16. 
VALENCIA-GARCÍA, Louie Dean (Ed.). Far-Right Revisionism and the End of History. New York: Routledge, 2020.

VALIM, Patricia; AVELAR, Alexandre de Sá. Negacionismo Histórico: entre a governamentalidade e a violação dos direitos fundamentais. Revista Cult, São Paulo, pp. 1-5, 03 set. 2020.

VINCENT, Gérard. Segredos da história e história do segredo. In: PROST, Antoine; VINCENT, Gérard (Orgs.). História da Vida Privada 5. Da Primeira Guerra a nossos dias. São Paulo: Cia das Letras, 1995. pp. 60-105.

VIRNO, Paolo. Saggio sulla negazione: Per una antropologia linguistica. Torino: Bollati Boringhieri, 2013.

YURCHAK, Alexei. Everything Was Forever, Until it Was no More: The Last Soviet Generation. Princeton-Oxford: Princeton University Press, 2005.

ZUBOFF, Shoshana. The Age of Surveillance Capitalism: The Fight for a Human Future at the New Frontier of Power. New York: PublicAffairs, 2019.

\section{NOTAS}

${ }^{1}$ Bolsista de produtividade do CNPq.

${ }^{2}$ Agradecimentos: Verônica Pereira, Henrique Estrada Rodrigues, Gessica Guimarães, Henrique Gaio, Viviane Araujo, Tamirez Fernandes, Magide Vieira. NEHM/UFOP, COMUM/UERJ. Apoio: CNPq, CAPES, FAPEMIG, INCT Proprietas e FAPERJ.

${ }^{3} \mathrm{Cf}$., em especial, The Intercept Brasil, 2020.

${ }^{4}$ Para Han, o Facebook e o Google trabalham como serviços secretos, pois lucram ao conhecer os desejos dos usuários, muitas vezes, sem que os mesmos o saibam. Haveria, assim, para o autor, uma passagem da biopolítica foucaultina para a "psicopolítica digital". O psicopoder seria mais eficiente que o biopoder, já que controla de dentro e não mais de fora (Han, 2016). Cf., também, entre outros, Zuboff (2019).

${ }^{5} \mathrm{~A}$ este respeito, cf. Transparência Internacional.

${ }^{6}$ É importante lembrar que Moro foi Ministro da Justiça do Governo Bolsonaro por 15 meses.

${ }^{7}$ Bolsonaro, por exemplo, em 7 de outubro de 2020, afirmou que encerrou a Lava Jato porque não há corrupção em seu governo.

${ }^{8}$ Como afirma Lynch (2018): "O conceito de revolução é aqui mobilizado em chave liberal, à maneira iluminista de um abade Sieyès, isto é, como um processo de ampla transformação promovido por uma sociedade civil cansada de privilégio e impunidade. Encabeçada por uma vanguarda de heróis, como foram outrora tenentes como Juarez Távora e Eduardo Gomes, que se levantaram contra a República Velha, a nova revolução de 1930 encontraria seus heróicos portadores em juízes como Sérgio Moro e promotores como 
Deltan Dallagnol.” Nessa direção, cabe ainda sublinhar que Rosanvallon (2020, p. 22), ao analisar certa independência do judiciário como parte da atual crise da democracia em escala global, destaca que a oposição entre direito e democracia não é nova, já que foi discutida nas revoluções americana e francesa. Nos dois casos, a questão da eleição de juízes foi colocada em prática, sendo que, no caso francês, foi revista posteriormente. No entanto, para o autor, na contemporaneidade, essa oposição teria se radicalizado por diversas razões (Cf. Rosanvallon, 2020). 